Research Paper

\title{
Salinomycin suppresses TGF- $\beta 1$-induced EMT by down-regulating MMP-2 and MMP-9 via the AMPK/SIRT1 pathway in non-small cell lung cancer
}

\author{
Ki-Eun Hwang ${ }^{*}$, Hyo-Jin Kim ${ }^{4}$, In-Sol Song1, Chul Park ${ }^{1}$, Jae Wan Jung ${ }^{1}$, Do-Sim Park², Seon-Hee Oh , \\ Young-Suk Kim ${ }^{\circledR}$ and Hak-Ryul Kim ${ }^{1 凶}$ \\ 1. Department of Internal Medicine, Wonkwang University, School of Medicine, Iksan, Jeonbuk 54538, Republic of Korea \\ 2. Department of Laboratory Medicine, Wonkwang University, School of Medicine, Iksan, Jeonbuk 54538, Republic of Korea \\ 3. Department of Premedicine, Chosun University, School of Medicine, Gwangju 61452, Republic of Korea \\ 4. Medical Convergence Research Center, Wonkwang University, Iksan, Jeonbuk 54538, Republic of Korea \\ "Contributed equally \\ $\square$ Corresponding authors: Professor Hak-Ryul Kim, Department of Internal Medicine, Wonkwang University, School of Medicine, Iksan, Jeonbuk 54538, \\ Republic of Korea, E-mail: kshryj@wku.ac.kr; Dr Young-suk Kim, Medical Convergence Research Center, Wonkwang University, Iksan, Jeonbuk 54538, Republic \\ of Korea, E-mail: kysima@wku.ac.kr \\ ( ) The author(s). This is an open access article distributed under the terms of the Creative Commons Attribution License (https://creativecommons.org/licenses/by/4.0/). \\ See http://ivyspring.com/terms for full terms and conditions.
}

Received: 2020.06.29; Accepted: 2020.10.15; Published: 2021.01.01

\begin{abstract}
Salinomycin (Sal) is a recently identified anti-tumor drug for treating several types of solid tumor; however, its effects on the migratory and invasive properties of non-small cell lung cancer (NSCLC) remain unclear. This study investigated the inhibitory effect underlying mechanisms of Salon transforming growth factor- $\beta 1$ (TGF- $\beta 1$ )-induced epithelial-to-mesenchymal transition (EMT) and cell migration. Sal solidly blocked cell migration and invasion enhancement by TGF- $\beta 1$-induced EMT, through recovering E-cadherin loss and suppressing mesenchymal markers induction, as well as TGF- $\beta 1$-mediated AMPK/SIRT signaling activity upregulation. The pharmacologic inhibition or knockdown of AMPK or SIRT1 can act synergistically with Sal to inhibit TGF- $\beta 1$-induced MMP-2 and MMP-9. In contrast, AMPK or SIRT1 upregulation can protect against TGF- $\beta 1$-induced MMP-2 and MMP-9 inhibition by Sal. Next we demonstrated that the MMP-2 and MMP-9 knockdown can act synergistically with Sal to inhibit TGF- $\beta 1$-induced EMT. Moreover, treatment of PMA of MMP activator increased TGF- $\beta 1$-induced MMP-2 and MMP-9, even with Sal. Our results demonstrate that Sal suppresses TGF- $\beta 1$-induced EMT by downregulating MMP-2 and MMP-9 through the AMPK/SIRT pathway, thereby inhibiting lung cancer cell migration and invasion.
\end{abstract}

Key words: Salinomycin, TGF- $\beta 1$, EMT, AMPK, SIRT, MMP, Lung cancer

\section{Introduction}

Non-small cell lung cancer (NSCLC) accounts for approximately $80 \%$ of all lung cancers, and few patients achieve long-term survival despite treatment advances over the past few decades. Metastasis, invasion, and drug resistance are the main factors contributing to relapse and death [1].

Epithelial-to-mesenchymal transition (EMT) is a process where cells undergo morphologic changes from a polarized epithelial phenotype to a highly motile mesenchymal phenotype. The switch of
E-cadherin to $\mathrm{N}$-cadherin is the critical event in EMT that makes single cells more motile and invasive [2-4]. Cells undergoing EMT also increase mesenchymal proteins synthesis and matrix metalloproteases (MMPs) expression. These extracellular matrix components stimulate integrin signaling and facilitate cell migration $[5,6]$. Therefore, elucidating the molecular mechanism that regulates E-cadherin, $\mathrm{N}$-cadherin, and MMP expression has become pivotal for understanding cancer invasion and metastasis. 
Transforming growth factor- $\beta 1$ (TGF- $\beta 1$ ) is involved in many biological processes, such as embryogenesis, wound healing, cell proliferation, differentiation, and EMT [7-9]. In cancer, TGF- $\beta$ acts as a suppressor in the early stages of tumorigenesis by inhibiting cell growth and inducing cell apoptosis. Conversely, in the later stages of tumor progression, it acts as a promoter, as TGF- $\beta$ suppresses the tumor cells' ability to be growth-arrested while undergoing EMT, which correlates with the increased invasiveness and metastasis [10].

Salinomycin (Sal) has been globally used in animal husbandry for many years. It is a potassium ionophore, isolated from Streptomyces albus, and was initially considered an antibiotic [11]. Recent studies show that Sal regulates apoptosis, proliferation, and differentiation in several cell types [11, 12]. A novel method has been developed for identifying agents that targeted breast cancer stem cells (CSCs) from approximately 16,000 compounds Gupta et al. [13]. Also Sal reportedly kills breast CSCs more effectively than the conventional anti-tumor drug paclitaxel. Sal's ability to eradicate CSCs, modulate EMT, and suppress the invasion capacity of several types of tumors has been reported in recent years [14-16]. However, the effects of Sal on the migratory and invasive properties of NSCLC cells and its underlying, remain unclear.

In the present study, we showed that MMP-2 and MMP-9 activity mediates Sal's anti-invasive and anti-migratory effects by downregulation through the AMPK/SIRT pathway, thereby inhibiting the invasion and metastasis of lung cancer cells.

\section{Materials and Methods}

Materials. Roswell Park Memorial Institute medium 1640 (RPMI 1640), fetal bovine serum (FBS), and antibiotics (penicillin and streptomycin) were obtained from GIBCO BRL Co. (Grand Island, NY, USA). Salinomycin, 3-(4,5-dimethyl-2-thiazolyl)-2,5diphenyl-2H-tetrazolium bromide (MTT), propidium iodide (PI), dimethyl sulfoxide, Sirtinol, and AICAR were purchased from Sigma (St. Louis, MO, USA). Recombinant human TGF- $\beta 1$ was purchased from R\&D Systems (Abingdon, UK). Affinity-purified monoclonal antibodies against mouse SIRT1 antibody were obtained from Abcam (Cambridge, UK). AMPK inhibitor Compound $C$ was purchased from Calbiochem (San Diego, CA, USA). MMP total activator PMA was purchased from Merck Millipore (Billerica, MA, USA). Antibodies against E-cadherin, N-cadherin, MMP-2, MMP-9, vimentin, phospho-AMPK, and AMPK were purchased from Cell Signaling Technology (Beverly, MA, USA). Anti-rabbit IgG-conjugated horseradish peroxidase
(HRP) antibodies and enhanced chemiluminescence (ECL) kits were purchased from Amersham Pharmacia Biotech (Buckinghamshire, UK).

Cell culture and viability test. Lung cancer cell lines A549 and H460 were purchased from the American Type Culture Collection (ATCC). These cell lines were grown in RPMI 1640 containing 100 units/mL penicillin, $0.1 \mathrm{mg} / \mathrm{mL}$ streptomycin, and 10\% FBS. Cells were incubated in a humidified atmosphere of $5 \% \mathrm{CO}_{2}$ in air at $37^{\circ} \mathrm{C}$ and maintained in log growth phase. Cell viability was determined by the MTT assay. After the cells were treated with the specified drugs, MTT was added to the cell suspension and incubated for $4 \mathrm{~h}$. The cells were then washed three times with phosphate-buffered saline (PBS; pH 7.4), and the insoluble formazan product was dissolved in dimethyl sulfoxide. The optical density (OD) at 595 $\mathrm{nm}$ was measured for each well using a microplate reader (Titertek Multiskan; Flow Laboratories, North Ryde, New South Wales, Australia). The OD resulting from formazan production in control cells was taken to denote $100 \%$ cell viability, and all other measurements were expressed as a percentage of this control value.

Tumor xenograft studies in nude mice. Five- to six-week-old BALB/c athymic nude mice (Charles River, Japan) were housed in cages with HEPA-filtered air (12-h light/dark cycle) and had ad libitum access to food and autoclaved water. H460 or H460 cells plus TGF- $\beta 1$ was injected subcutaneously (s.c.) into both hind legs of each mouse. The mice were randomly assigned to three experimental groups $(\mathrm{n}=$ 5 each) when the implanted tumors reached a volume of $90-130 \mathrm{~mm}^{3}$. Each group was monitored until tumors reached a volume of $1,300 \mathrm{~mm}^{3}$, or for $21 \mathrm{~d}$.

Scratch-migration assay. A549 and $\mathrm{H} 460$ cells were cultured in 6-well dishes (seeding density $1 \times 10^{6}$ cells/well). Confluent cell monolayers were disrupted by standardized wound scratching using a sterile $200-\mu \mathrm{L}$ pipette tip and incubated in a culture medium with $1 \%$ FBS, with or without $5 \mathrm{ng} / \mathrm{mL}$ TGF- $\beta 1,10 \mu \mathrm{M}$ Sal, TGF- $\beta 1$ plus $5 \mu \mathrm{M}$ Sal, or TGF- $\beta 1$ plus $10 \mu \mathrm{M}$ Sal, for $48 \mathrm{~h}$. Migration of cells into the bare area and recovery of the monolayer was evaluated every $12 \mathrm{~h}$ for $48 \mathrm{~h}$ using a phase contrast microscope, and was digitally photographed (Nikon Diaphot 300; Nikon, Tokyo, Japan).

Electric cell-substrate impedance sensing (ECIS) wound healing assay. Wound healing assays were performed using ECIS (Applied BioPhysics, Troy, NY, USA) technology, following our previously established protocol [17]. For wound healing assays, confluent A549 cells monolayers cultured on ECIS plates were subjected to an elevated voltage pulse of $60 \mathrm{kHz}$ frequency, $3.5 \mathrm{~V}$ amplitude, and $30 \mathrm{~s}$ duration, 
leading to the death and detachment of cells present on the small active electrode, resulting in a wound normally healed by cells surrounding the small active electrode that have not been subjected to the elevated voltage pulse. Wound healing was then assessed by continuous resistance measurements for $24 \mathrm{~h}$.

Matrigel invasion assay. Cell invasion assay kits (Chemicon International, Temecula, CA) were used to detect cell invasion, following the manufacturer's protocol. Cells were resuspended in culture media and incubated in a chemo invasion chamber. A549 and $\mathrm{H} 460$ cells were seeded at a density of $2 \times 10^{4}$ per insert and cultured for $12 \mathrm{~h}$. Next, the cells were placed in wells containing the same medium plus TGF- $\beta 1$ (5 ng/mL), with or without Sal. After $48 \mathrm{~h}$, non-invading cells were removed using cotton swabs. The invasive capability of cells was measured as per the manufacturer's recommendations. Photomicrographs of the invasive cells were taken in five predetermined fields (magnification 200×) and quantification of the stained cells was performed by dissolving cells in $10 \%$ acetic acid and measuring the $\mathrm{OD}$ at $540 \mathrm{~nm}$.

ECIS invasion assay. Electrode arrays were obtained from Applied BioPhysics (Troy, NY, USA), and ECIS invasion assays were performed as described previously [18]. ECIS array wells were precoated with a solution of $200 \mu \mathrm{g} / \mathrm{mL}$ gelatin in 0.15 $\mathrm{mol} / \mathrm{L} \mathrm{NaCl}$. After $15 \mathrm{~min}$ of incubation to allow for gelatin adsorption, the gelatin solution was aspirated, and the electrode-containing wells were rinsed twice with PBS. They were then partially filled with $200 \mu \mathrm{L}$ of human umbilical vein endothelial cell (HUVEC) medium and allowed to equilibrate for 15 to $60 \mathrm{~min}$ in a humidified $\mathrm{CO}_{2}$ incubator. Approximately $1 \times 10^{5}$ HUVECs were added to each well in $200 \mu \mathrm{L}$ HUVEC medium. The attachment and spreading of cells into the ECIS wells was followed by impedance measurements using ECIS. HUVECs were challenged with monodispersed cell suspensions of A549 cells (20 $\times 10^{5} / \mathrm{mL}$ ) in $50 \mu \mathrm{L}$ of fresh HUVEC medium. Triplicate wells were used for each treatment. The cells were treated with $1 \%$ FBS, with or without TGF- $\beta 1$, Sal, and TGF- $\beta 1$ plus Sal. The impedance of the challenged endothelial cell layer was monitored via ECIS for the next $12-40 \mathrm{~h}$.

Western blotting. Cells were harvested and lysed in radioimmunoprecipitation assay buffer $(50 \mathrm{mM}$ Tris-Cl [pH, 7.4], 1\% NP40, $150 \mathrm{mM} \mathrm{NaCl}, 1 \mathrm{mM}$ EDTA, $1 \mathrm{mM}$ phenylmethylsulfonyl fluoride, 1 $\mu \mathrm{g} / \mathrm{mL}$ each of aprotinin and leupeptin, and $1 \mathrm{mM}$ $\mathrm{Na}_{3} \mathrm{VO}_{4}$ ). After centrifugation at $12,000 \times g$ for $30 \mathrm{~min}$, the supernatant was collected, and the protein concentration was determined by the Bradford method (Bio-Rad Protein Assay; Hercules, CA, USA).
Equal amounts of protein were separated by $10 \%$ sodium dodecyl sulfate-polyacrylamide gel electrophoresis (SDS-PAGE) under reducing conditions and were subsequently transferred to polyvinylidene difluoride membranes. The membranes were blocked with $5 \%$ skim milk in TBS-T (25 mM Tris [pH, 7.6], $138 \mathrm{mM} \mathrm{NaCl}$, and $0.05 \%$ Tween-20) for $1 \mathrm{~h}$ and probed with primary antibodies (at 1:1000-1:5000). After washing, the membranes were incubated with the relevant HRP-conjugated secondary antibody (at 1:2000$1: 10,000)$. Immunoreactive signals were detected using an ECL detection system.

Gelatin zymography. To analyze the activity of MMP-2 and MMP-9, we respectively incubated A549 and $\mathrm{H} 460$ cells $\left(1 \times 10^{5}\right.$ cells/well $)$ in a 24-well plate for $24 \mathrm{~h}$. After serum starvation for $24 \mathrm{~h}$, the supernatant was collected after treatment with TGF- $\beta 1$ in the absence or presence of Sal, and subjected to SDS-PAGE in 10\% polyacrylamide gel with $1 \mathrm{mg} / \mathrm{mL}$ gelatin. After electrophoresis, the gels were incubated in $2.5 \%$ Triton X-100 $\left(1 \mathrm{~h}, 37^{\circ} \mathrm{C}\right)$, followed by overnight incubation in $50 \mathrm{mM}$ Tris- $\mathrm{HCl}$ (pH 7.8), $5 \mathrm{mM} \mathrm{CaCl}_{2}, 0.02 \% \mathrm{NaN}_{3}$, and $0.02 \%$ Brij gels. They were stained with $2.5 \%$ Coomassie Blue R-250 (Bio-Rad) for $45 \mathrm{~min}$, followed by destaining in deionized water with $10 \%$ acetic acid and $20 \%$ methanol. The gels were scanned and density analysis of the bands was performed using Photoshop CS4.0 (Alphalmager 2000, Alpha Innotech, San Leandro, CA).

Gene silencing. Pooled small interfering RNA (siRNA) oligonucleotides against SIRT1 were purchased from Cell Signaling Technology, and AMPK, MMP-2, and MMP-9 were purchased from Life Technologies. Twenty-four hours after seeding, the cells were transfected with $100 \mathrm{nM}$ pooled oligonucleotide mixture using Lipofectamine 2000 (Invitrogen), according to the manufacturer's protocol. Twenty-four hours after transfection, the media were removed, and cells were treated with the indicated drugs. Gene silencing efficacy by siRNA was assessed by western blot analysis.

Preparation of the recombinant adenovirus. To prepare SIRT1-expressing adenovirus, human SIRT1 cDNA was cloned into the KpnI and Xhol sites of pENTR 2B (Invitrogen), and the SIRT1 cDNA insert was transferred to the $\mathrm{pAd} / \mathrm{CMV} / \mathrm{V} 5$-DEST vector by the Gateway system using LR Clonase (Invitrogen). The plasmids were linearized with PacI (Promega, Madison, WI) and transfected into A549 and H460 cells using Lipofectamine 2000 (Invitrogen). As a control, the pAd/CMV/V5-GW/lacZ vector (Invitrogen) was used to produce lacZ-bearing adenovirus. 
Statistical analysis. Each experiment was performed at least thrice, and all the values were expressed as the mean \pm standard deviation (SD) of triplicate samples. Student's $t$-test was used to determine statistical significance. Values with $p<0.05$ were considered statistically significant.

A

A549

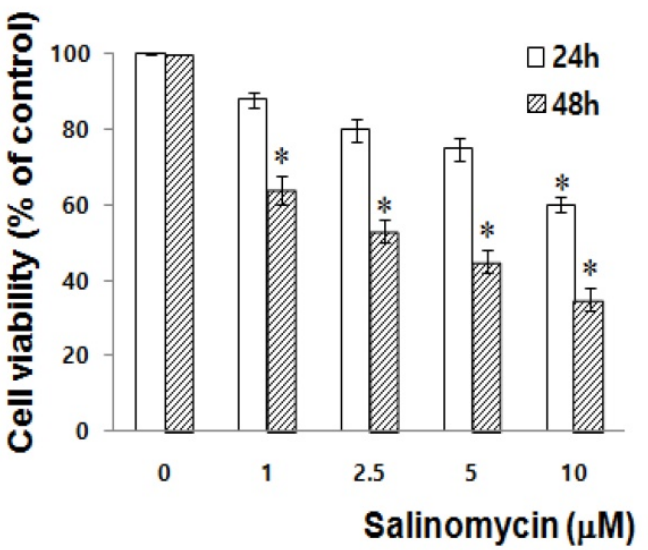

B

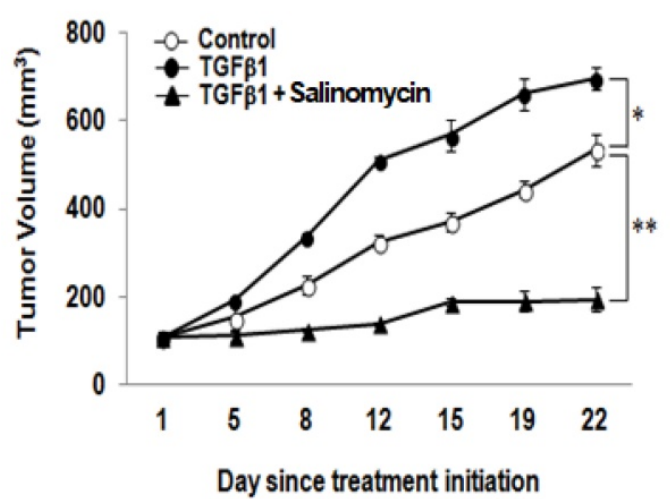

D

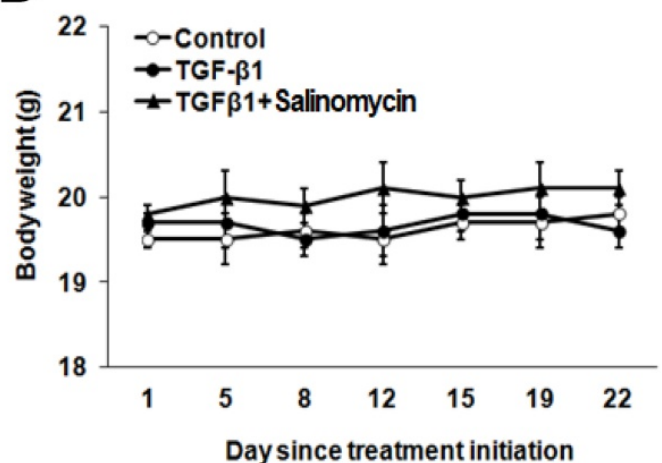

\section{Results}

The Effects of Sal on the cytotoxicity of NSCLC cells. To test Sal's effects on NSCLC cell viability, we treated the lung cancer cell lines, A549 and H460, with a range of Sal doses $(0,1,2.5,5$, and $10 \mu \mathrm{M})$ for $24 \mathrm{~h}$ and $48 \mathrm{~h}$. We observed that Sal had asignificanteffect, inhibiting A549 and H460 growth (Figure 1A) in a dose- and time-dependent manner.

H460

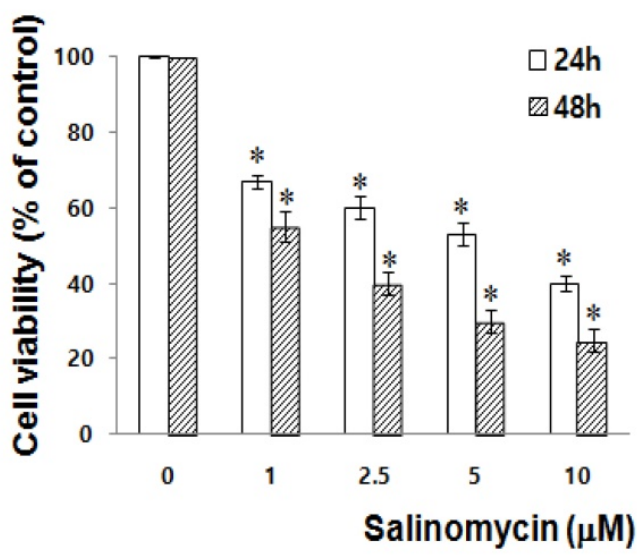

C

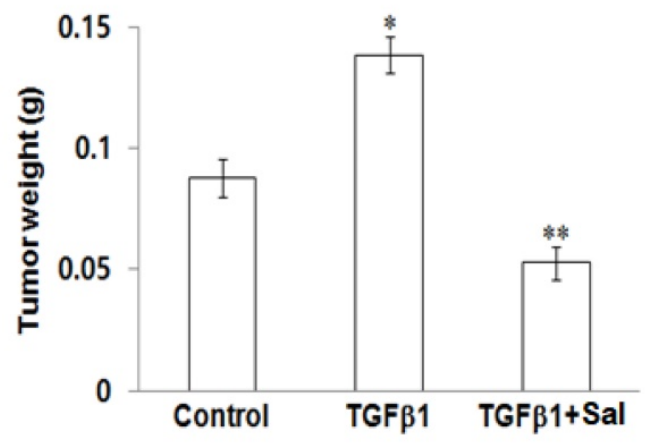

Figure 1. Sal's effects on NSCLC cells growth. (A) A549 and H460 cells were treated with different concentrations of Sal for 24 or 48 h, and viability was determined using the MTT assay. The viability of control cells was set at $100 \%$, and survival relative to the control is presented. The data represent the means \pm S.D. of three independent experiments. *, $p<0.05$, compared with the control. (B) Athymic nude mice were subcutaneously injected with $2 \times 10^{6} \mathrm{H} 460$ cells $(0.2 \mathrm{~mL}$ cell suspension) in both hind legs. When the implanted tumors reached a volume of $90-130 \mathrm{~mm}^{3}$, mice were assigned randomly to one of the following experimental groups ( $\mathrm{n}=5$ each): no treatment, TGF- $\beta 1$, and TGF- $\beta 1$ plus Sal (5 mg/kg, intraperitoneally, daily for three weeks). Tumor dimensions were measured three times a week. The tumor volume was estimated using the formula: volume $=L \times W^{2} / 2$. Points, mean of five animals; bars, SD. ${ }^{*}, p<0.01$, compared with the control.(C)The tumors were weighed. The data represent the mean \pm SD of five animals. * $p$ $<0.01$, compared with the control. (D) Body weights of the mice were insignificantly different among all groups. 
Sal suppresses lung cancer tumor growth in vivo. To demonstrate Sal's inhibitory effects on tumor growth in xenografts, we performed an anti-tumor study using athymic nude mice subcutaneously injected with H460 cells plus TGF- $\beta 1$. The animals in the experimental group were intraperitoneally injected with Sal $(5.0 \mathrm{mg} / \mathrm{kg})$ every day, whereas those in the control group were injected with PBS.

Sal treatment significantly reduced tumor growth compared with the control group (Figure 1B). Furthermore, the mice injected with Sal had a considerably smaller tumor volume than the controls (Figure 1C). Mice body weight on subsequent days after the first drug injection was not significantly different among the experimental groups (Figure 1D).

Sal inhibits TGF- $\beta 1$-induced A549 and H460 cell migration. We assessed Sal's effects on migration using scratch-migration assay and ECIS wound healing assay to investigate its potential role in inhibiting lung cancer cell migration. TGF- $\beta 1$ enhanced A549 and H460 cell migration, whereas Sal dose-dependently inhibited it, as observed in a conventional scratch-migration assay (Figure 2A). Using an ECIS-based quantitative real-time assay to investigate A549 cell migration, we confirmed that TGF- $\beta 1$-treated cells showed increased resistance, whereas the combined Sal plus TGF- $\beta 1$ treatment showed decreased resistance (Figure 2B). These results indicate that Sal effectively prevention of TGF- $\beta 1$-induced lung cancer cell migration.

Sal inhibits TGF- $\beta 1$-induced A549 and H460 cell invasion. We investigated Sal's effects on lung cancer cell invasion after TGF- $\beta 1$ stimulation using a Matrigel invasion assay and an ECIS invasion assay. TGF- $\beta 1$ treatment increased A549 and H460 cell invasion, compared with untreated cells, whereas Sal treatment inhibited lung cancer cell invasion in a dose-dependent manner. The quantitative analysis further confirmed Sal's inhibitory effect on invasion (Figure 2C).

In the ECIS-based invasion assay, established human umbilical vein endothelial cell (HUVEC) layers were challenged using A549 cells. The decreased resistance indicated that direct interactions occurred between the A549 cells and the HUVECs, leading to A549 cell extravasation on the substratum. TGF- $\beta 1$ treatment induced a steep drop in resistance compared with untreated controls, demonstrating that TGF- $\beta 1$ increased invasiveness. Sal dose-dependently inhibited the invasive potential of A549 cells even with TGF- $\beta 1$ (Figure 2D). These results indicated that Sal could effectively inhibit TGF- $\beta 1$-induced lung cancer cell invasion.

Sal inhibits TGF- $\beta 1$-induced EMT through the AMPK/SIRT1 signaling pathway. We examined EMT marker expression in TGF- $\beta 1$ - or TGF- $\beta 1$ plus Sal treated NSCLC cells to investigate Sal's effects on TGF- $\beta 1$-induced EMT. E-cadherin expression declined in response to TGF- $\beta 1$, whereas $\mathrm{N}$-cadherin and vimentin expressions increased. However, Sal reversed vimentin-induced TGF- $\beta 1$ expression and inhibited the TGF- $\beta 1$-induced cadherin switch (Figure $3 \mathrm{~A})$. Several studies have reported that the TGF- $\beta 1$-induced SIRT1/AMPK signaling pathways are consistent with tumorigenicity $[19,20]$. Next, we examined the effects of Sal on TGF- $\beta 1$-induced AMPK/SIRT1 activation in A549 and H460 cells. TGF- $\beta 1$ induced SIRT1 expression levels and AMPK phosphorylation levels, as well as MMP-2 and MMP-9 expression levels, in NSCLC cells, In contrast, Sal treatment suppressed the TGF- $\beta 1$-induced SIRT1 expression and AMPK phosphorylation in a concentration-dependent manner (Figure 3B).

Involvement of $A M P K$ in the inhibition of TGF- $\beta 1$-induced MMP-2 and MMP-9 expression by Sal. To determine whether p-AMPK inhibition affected MMP-2 and MMP-9 expression, we treated the cells with Sal, followed by Compound C, an AMPK inhibitor. Compound C expectedly enhanced Sal's suppressive effect on TGF- $\beta 1$-induced MMP-2 and MMP-9 expression in NSCLC cells, as revealed through Western blotting (Figure 4A). To rule out the chemical inhibitor's non-selective effects, we examined how Sal's TGF- $\beta 1$-induced MMP-2 and MMP-9 downregulation affects AMPK siRNA-transfected cells. AMPK silencing, in combination with Sal treatment, augmented the downregulation of TGF- $\beta 1$-induced MMP-2 and MMP-9 expression in A549 and H460 cells (Figure 4B). These findings reveal that pharmacologic inhibition or AMPK knockdown synergistically acted with Sal to inhibit TGF- $\beta 1$-induced MMP-2 and MMP-9 expression.

Next, we examined whether AMPK upregulation could confer protection against Sal's inhibitory effect on TGF- $\beta 1$-induced MMP-2 and MMP-9 expression. As shown in Figure 4C, the treatment of AICAR of AMPK activator increased TGF- $\beta 1$-induced MMP-2 and MMP-9 expression, in NSCLC cells, even in the presence of Sal. These results indicate that AMPK is involved in inhibiting TGF- $\beta 1$-induced MMP-2 and MMP-9 expression by Sal.

Involvement of SIRT1 in inhibiting TGF- $\beta 1$-induced $M M P-2$ and MMP-9 expression by Sal. We treated the cells with pharmacologic SIRT1 inhibitor, sirtinol, or knocked down SIRT1 by introducing as iRNA for SIRT1 to determine the role of SIRT1 in inhibiting TGF- $\beta 1$-induced MMP-2 and MMP-9 expression by Sal. When TGF- $\beta 1$-induced A549 and H460 cells were 
treated with sirtinol plus Sal, MMP-2, and MMP-9 expression was attenuated (Figure $5 \mathrm{~A}$ ). In the same way, Figure 5B shows the attenuating effect of SIRT1 siRNA plus Sal treatment on TGF- $\beta 1$-induced MMP-2 and MMP-9 expression. These findings indicated that the SIRT1 pharmacologic inhibition or knockdown could act synergistically with Sal to inhibit TGF- $\beta 1$-induced MMP-2 and MMP-9 expression.
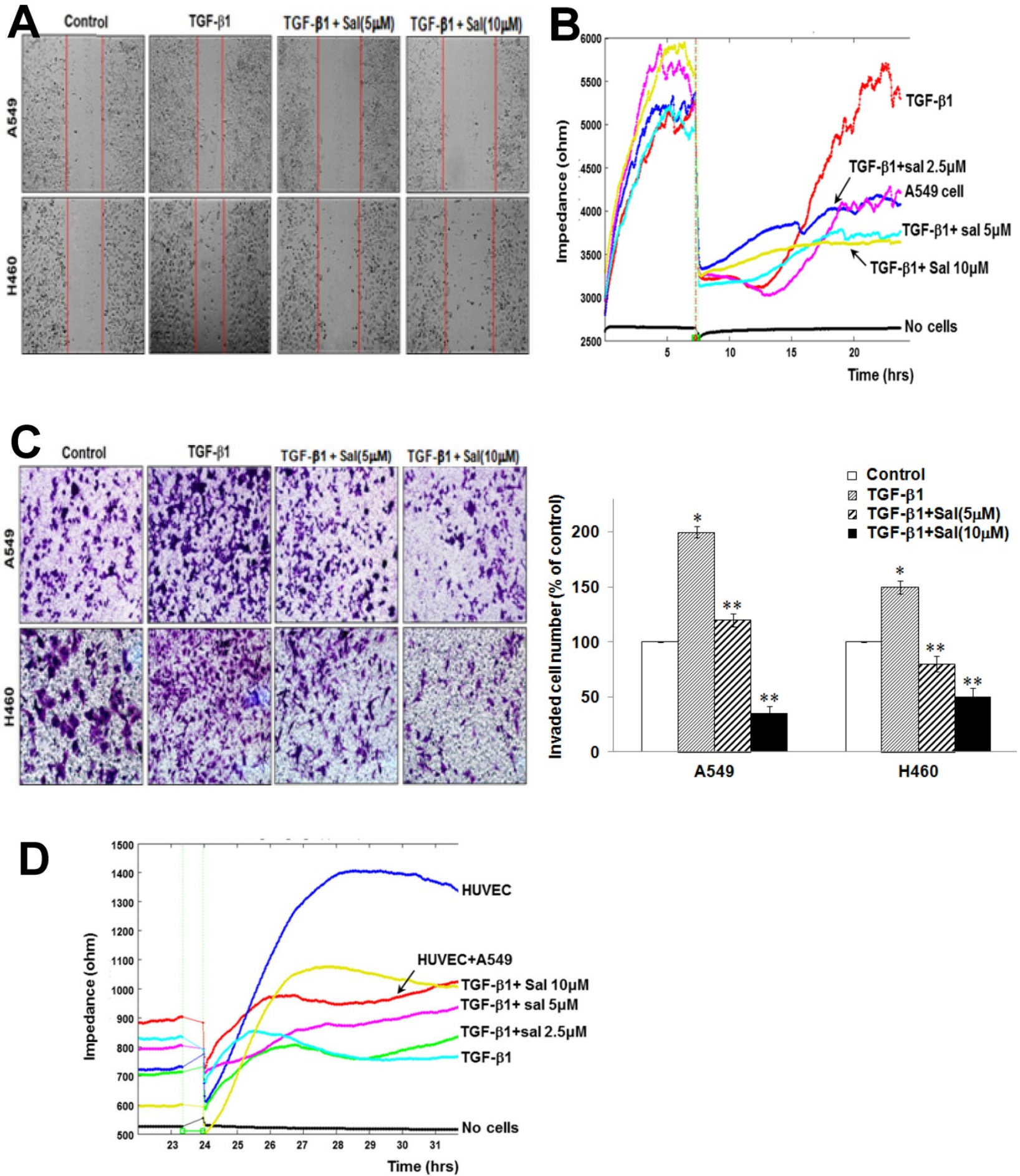

Figure 2. Sal's effects on TGF- $\beta 1$-induced A549 and H460 cell migration and invasion. (A) Cell migration was evaluated by scratch assay. The confluent A549 and H460 monolayer was scratched with a pipette tip and washed to remove debris. Fresh medium containing $0.5 \%$ serum was then added. Red lines indicate cell edges at the $\mathrm{T}_{0}$ point. Representative pictures are shown. (B) For the ECIS migration assay, A549 cells were stimulated with $5 \mathrm{ng} / \mathrm{mL}$ TGF- $\beta 1$ for $2 \mathrm{~h}$ and then incubated with $0,2.5,5$, and $10 \mu \mathrm{M}$ Sal for $48 \mathrm{~h}$. Then, cell migration was assessed by continuous resistance measurements for $40 \mathrm{~h}$. (C) Effects of Sal on A549 and H460 cell invasion in a $200 \times$ light microscope after crystal violet staining by Matrigel invasion assay, as described in Materials and Methods. Matrigel invasion of A549 and H460 cells, as counted in five random views. The data represent the mean \pm SD of three independent experiments. *, $p<0.01$, compared with the control;**, $p<0.05$, compared with the TGF- $\beta 1$ group. (D) For the ECIS invasion assay, resistance changes in the impedance were recorded at $4 \mathrm{kHz}$, as confluent layers of HUVECs were challenged with A549 cell suspensions. The control curve represents HUVECs that received media without A549 cells. A549 cells were treated as described in Material and Methods, and resistance changes were monitored for $40 \mathrm{~h}$. 


\section{A}

A549

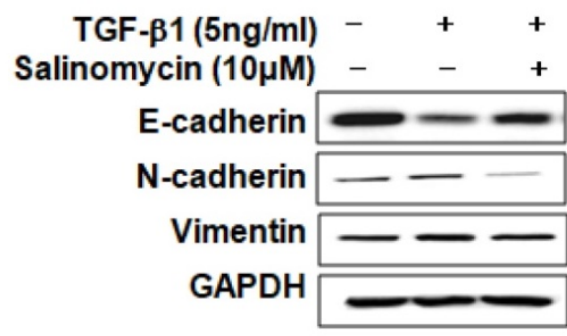

H460

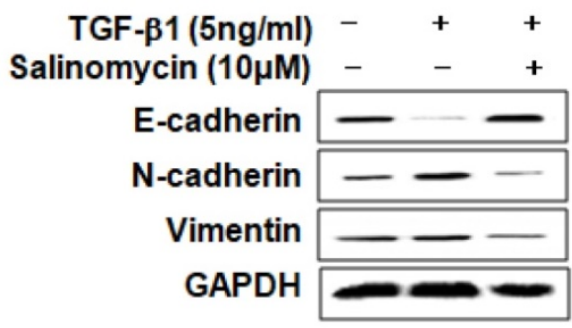

A549

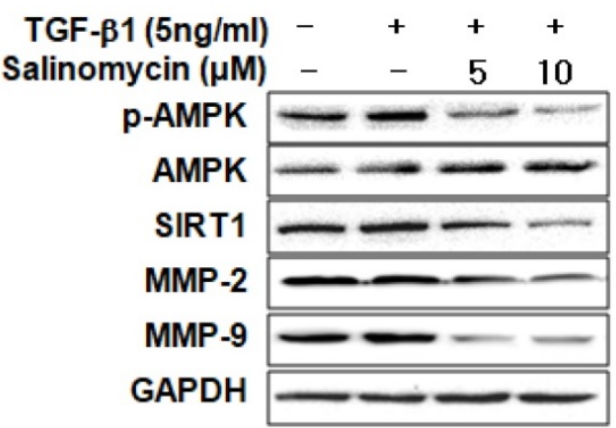

$\mathrm{H} 460$

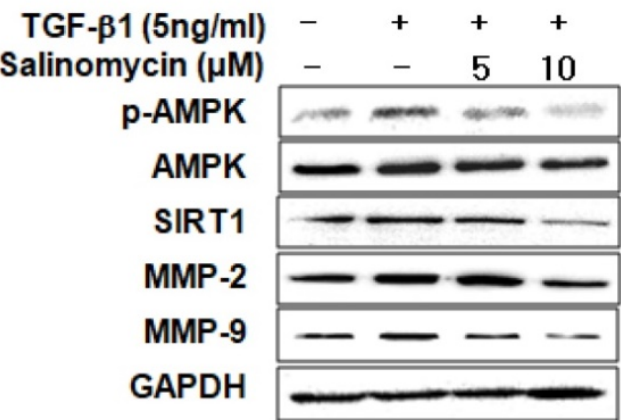

Figure 3. Effects of Sal on TGF- $\beta 1$-induced EMT through the AMPK/SIRT1 signaling pathway. (A) A549 and H460 cells were treated with 5 ng/mL TGF- $\beta 1$ and $10 \mu M$ Sal for 48 h. Cell lysates were used to measure E-cadherin, N-cadherin, and vimentin level. (B) The cells were treated with $5 \mathrm{ng} / \mathrm{mL}$ TGF- $\beta 1$ and Sal $(5$ or $10 \mu M)$, and AMPK/SIRT1-related protein levels were examined through immunoblotting. Similar data were obtained from three independent experiments.

We also examined whether SIRT1 upregulation could block TGF- $\beta 1$-induced MMP-2 and MMP-9 inhibition by Sal. For this, we introduced a SIRT1-expressing adenovirus into A549 and H460 cells. As shown in Figure 5C, SIRT1 overexpression treatment markedly increased TGF- $\beta 1$-induced MMP-2 and MMP-9 expression in A549 and H460 cells, even in the presence of Sal. Altogether, these results indicate that SIRT1 is involved in inhibiting TGF- $\beta 1$-induced MMP-2 and MMP-9 expression by Sal.

Sal inhibits TGF- $\beta 1$-induced EMT in NSCLC cells via attenuation of the MMP-2 and MMP-9 signaling pathway. Sal's suppressive effect on tumor cell migration and invasion points to the prior MMP expression regulation because these proteins play an essential role in local proteolysis of EMT and cell migration [21, 22]. As shown in Figure 6A, gelatin zymography showed that MMP-2 and MMP-9 activity in the TGF- $\beta 1$ plus Sal-treated cells was lower than that of TGF- $\beta 1$-treated cells. We knocked down MMP-2 and MMP-9 by introducing siRNAs to determine their role in TGF- $\beta 1$-induced EMT of NSCLC cells. The results showed that MMP-2 siRNA treatment, combined with Sal, led to TGF- $\beta 1$-induced EMT attenuation (Figure 6B). In the same way, MMP-9 siRNA treatment combined with Sal led to TGF- 31 -induced EMT attenuation (Figure 6C). These findings demonstrated that MMP-2 and MMP-9 knockdowns synergistically act with Sal to inhibit TGF- $\beta 1$-induced EMT.

We examined whether total MMP upregulation could confer protection against TGF- $\beta 1$-induced EMT attenuation by Sal. We induced MMP expression in MMP activator PMA-treated A549 and H460 cells. As shown in Figure 6D, MMP activator PMA treatment increased TGF- $\beta 1$-induced MMP-2 and MMP-9 expression levels, even with Sal. In summary, these results indicated that MMP is involved in inhibiting TGF- $\beta 1$-induced EMT by Sal.

\section{Discussion}

In the present study, we re-evaluated Sal's therapeutic potential for NSCLC treatment and 
clarified its molecular mechanisms. We showed that Sal inhibited TGF- $\beta 1$-induced EMT and suppressed lung cancer migration and invasion, which involved the AMPK/SIRT1-mediated signaling pathway.

EMT enhances cell invasion, migration, and proliferation, by conferring certain cell traits to cancer cells. Various signals induce the EMT program of cancer cells, such as the TGF- $\beta$ pathway from the nearby microenvironment [23, 24]. Sal is useful for chemotherapy and is involved in the proliferation, invasion, and EMT of cancer cells. Based on previous reports, Sal induced the expression of EMT markers, such as Snail, vimentin, and Zeb-1, and decreased E-cadherin expression [25, 26]. In contrast, other studies have proven that Sal reversed EMT in several cancer types [27, 28]. Here, we have demonstrated that Sal reversed TGF- $\beta 1$-induced EMT and inhibited NSCLC cell migration and invasion. These results suggest that Sal may exert anti-cancer effects by reversing EMT.

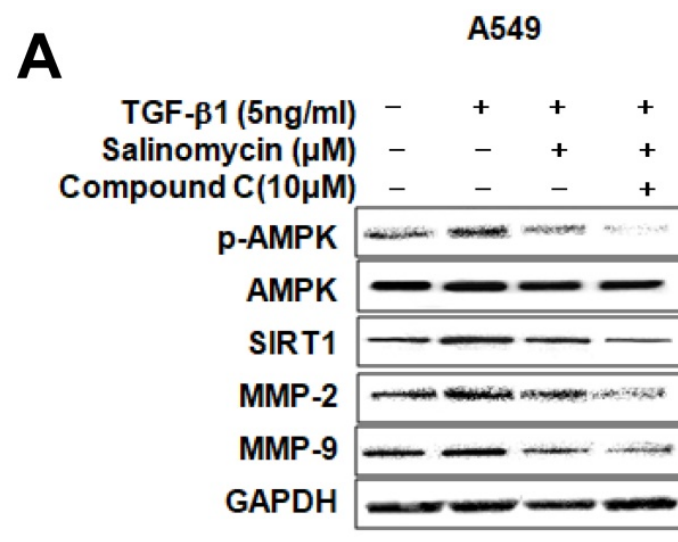

A549

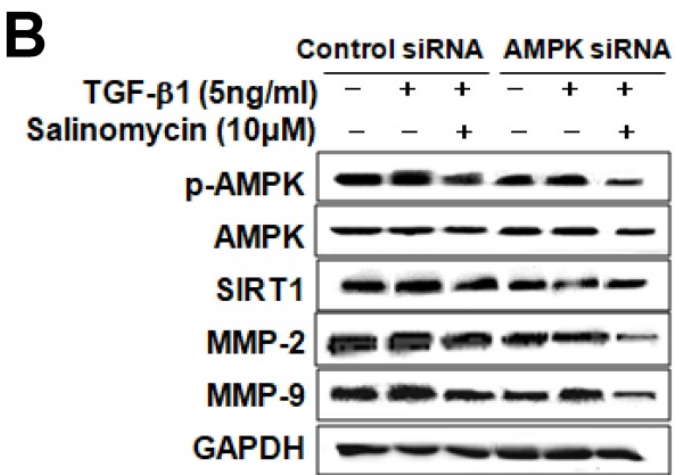

A549

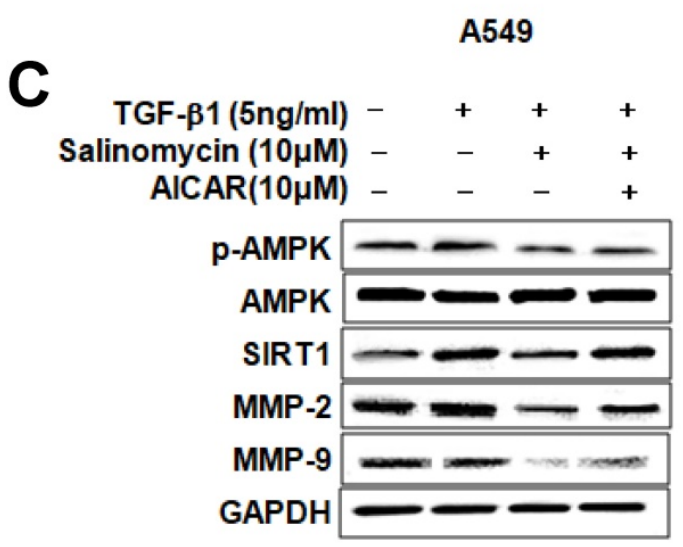

H460

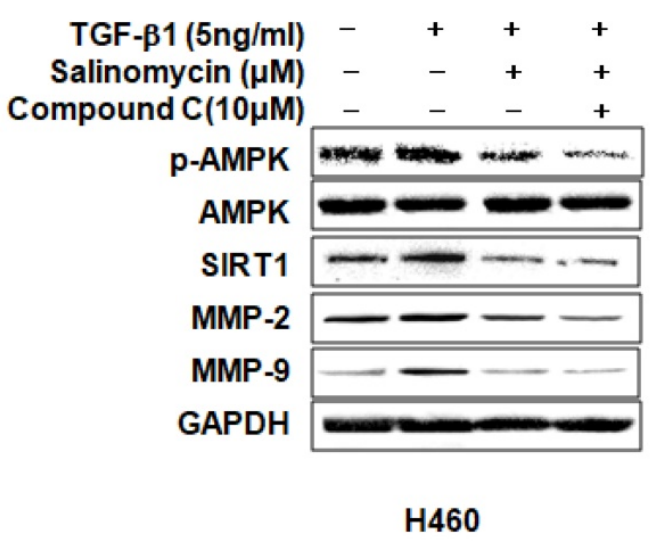

Control SIRNA AMPK siRNA

TGF-ק1 (5ng/ml) $-++\frac{++}{-+}$

Salinomycin $(10 \mu \mathrm{M})-\ldots+\ldots+$

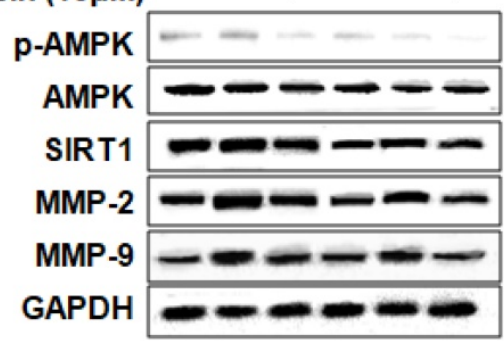

$\mathrm{H} 460$

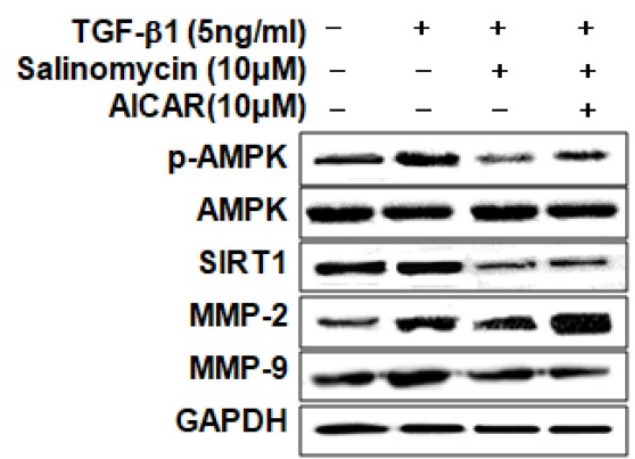

Figure 4. AMPK involvement in TGF- $\beta 1$-induced AMPK/SIRT1 signaling by Sal. (A, B) The Effects of AMPK inhibition on TGF- $\beta 1$-induced AMPK/SIRT1 signaling. A549 and H460 cells were treated with an AMPK inhibitor, Compound C, or transfected with AMPK siRNA, and then further incubated in the presence of Sal for $24 \mathrm{~h}$. The cell lysates were routinely prepared, and changes in signaling-mediated hallmarks were determined through Western blotting. (C) The cells were treated with an AMPK activator, AICAR, and then further incubated in the presence of Sal for $24 \mathrm{~h}$. 
A
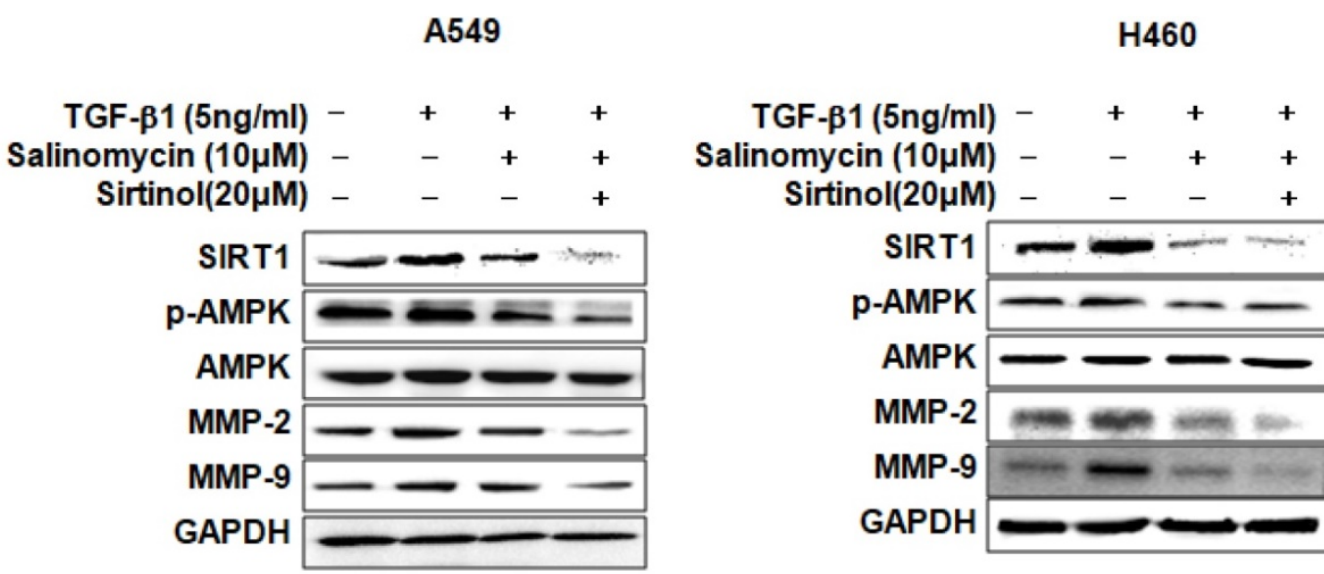

B

A549

H460

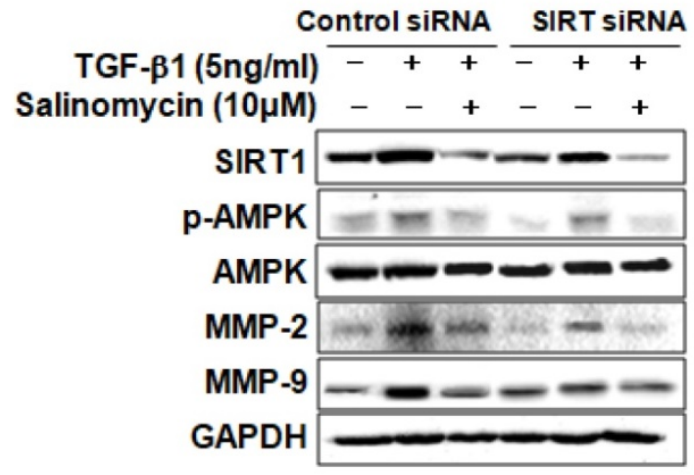

C

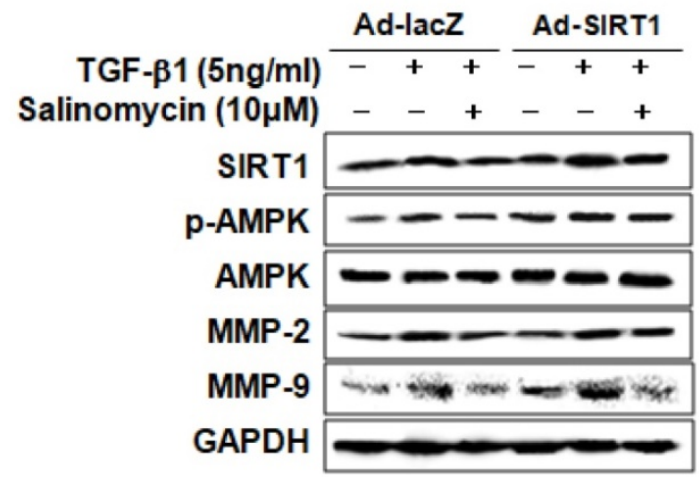

A549

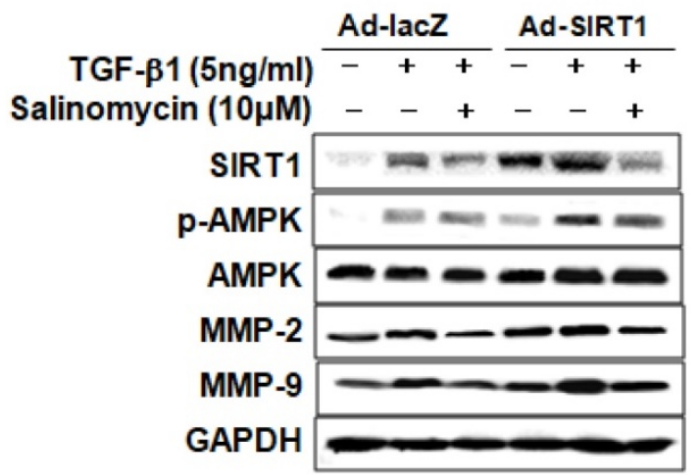

Figure 5. SIRT1 involvement in TGF- $\beta 1$-induced AMPK/SIRT1 signaling by Sal. (A, B) Effects of SIRT1 inhibition on TGF- $\beta 1$-induced AMPK/SIRT1 signaling. The cells were treated with a SIRT1 inhibitor, sirtinol, or transfected with SIRT1 siRNA, and then further incubated in the presence of Sal for $24 \mathrm{~h}$. (C) Effects of SIRT1 activation on TGF- $\beta 1$-induced AMPK/SIRT1 signaling. The cells were transfected with Ad-lacZ or Ad-SIRT1 and then further incubated in the presence of Sal for $24 \mathrm{~h}$. The cell lysates were routinely prepared, and alterations in signaling-mediated hallmarks were determined through Western blotting.

Next, we examined AMPK expression to elucidate the specific mechanism of Sal's inhibitory effects. AMPK reportedly participates in several processes related to cell growth, energy homeostasis, metabolic diseases, and cancer cells. Recently, several studies have shown that the AMPK pathway is involved in regulating invasion and migration by reducing MMP. Also, AMPK activation is required in EMT inhibition via regulation by EMT-related makers. Thus, AMPK signaling modulation may be an essential factor in preventing cancer development and metastasis [29-31]. As shown in Figure 3-4, Sal reduced TGF- $\beta 1$-induced AMPK phosphorylation. These results suggest that AMPK can influence Sal's inhibitory effect on EMT, migration, and invasive potential. 


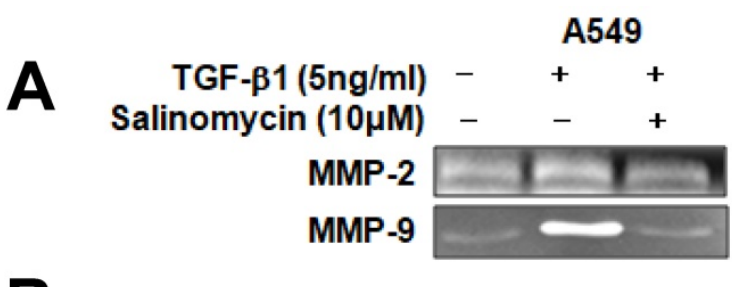

A549

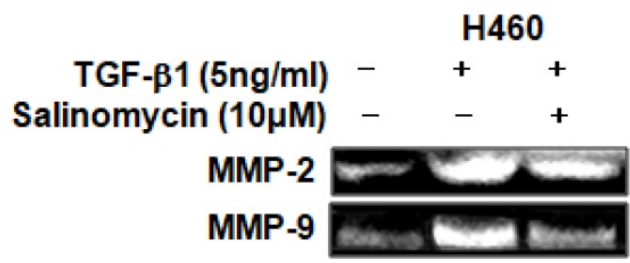

H460

Control SIRNA MMP-2 SIRNA

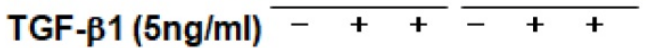
Salinomycin $(10 \mu \mathrm{M})--+--+$

C

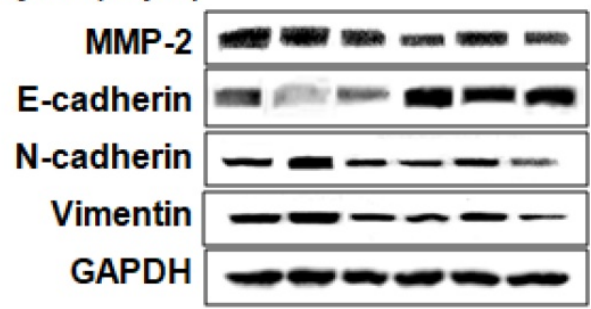

A549

Control siRNA MMP-9 siRNA

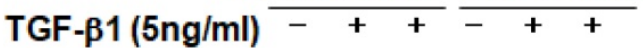
Salinomycin $(10 \mu \mathrm{M})--+--+$

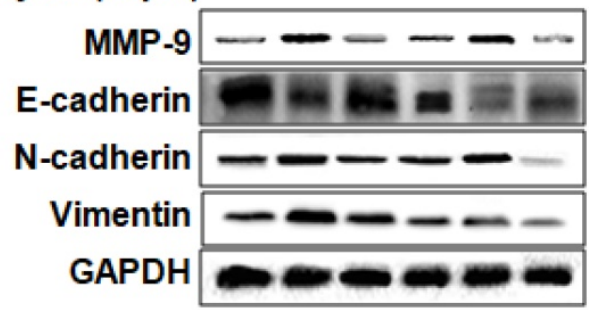
Sali

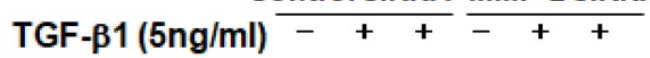

Control siRNA MMP-2 SIRNA

Salinomycin $(10 \mu \mathrm{M})-{ }_{-}+-+$

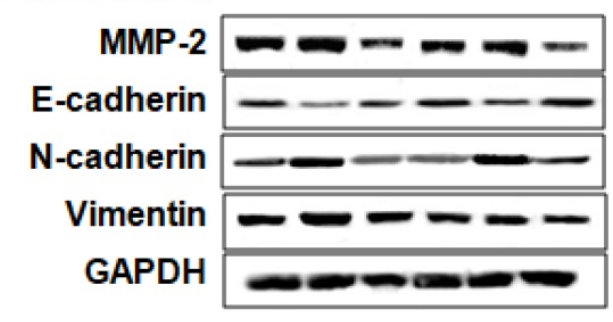

\section{H460}

Control siRNA MMP-9 siRNA

TGF-B1 (5ng/ml) -++++

Salinomycin $(10 \mu \mathrm{M})-{ }_{-}-{ }_{-}$

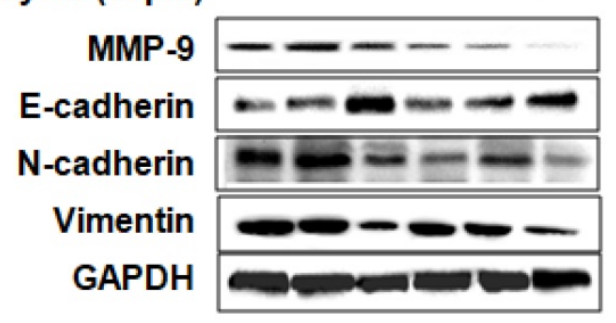

D

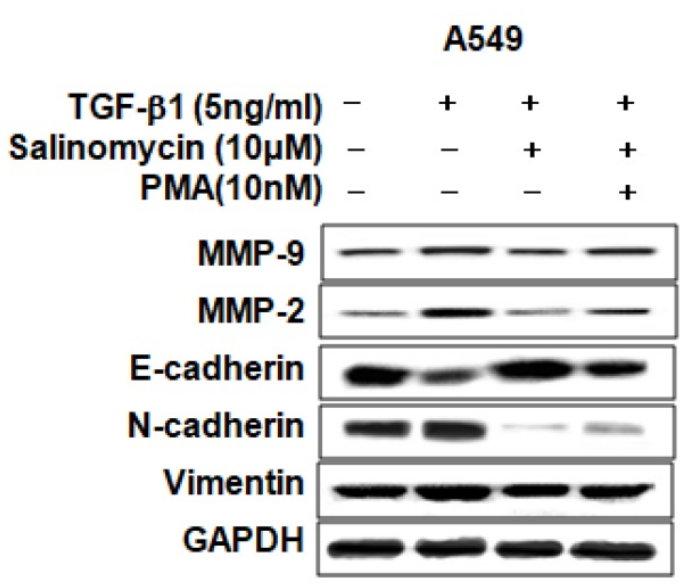

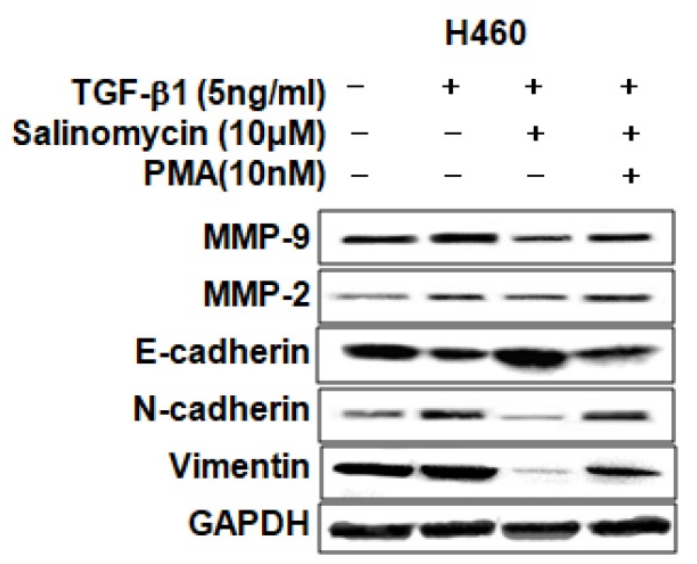

Figure 6. Sal's effects on TGF- $\beta 1$-induced EMT through MMP- 2 and MMP-9 signaling. (A) A549 and H460 cells were stimulated with $5 \mathrm{ng} / \mathrm{mL}$ TGF- $\beta 1$ for $2 \mathrm{~h}$ and then incubated with $10 \mu \mathrm{M}$ Sal for $24 \mathrm{~h}$. The supernatants were analyzed by gelatin zymography to measure MMP-2 and MMP-9 expression. (B, C) Effects of MMP-2 or MMP-9 inhibition on TGF- $\beta$ 1-induced EMT by Sal. The Cells were transfected with MMP-2 or MMP-9 siRNA and then further incubated in the presence of Sal for $24 \mathrm{~h}$. (D) The cells were treated with an MMP total activator, PMA, and then incubated further in the presence of Sal for $24 \mathrm{~h}$. The cell lysates were routinely prepared, and alterations in EMT hallmarks were determined through Western blotting. Similar data were obtained from three independent experiments.

SIRT1 belongs to the class III histone deacetylase (HDAC) family, where its members are mainly located in the nucleus and play essential roles in cell proliferation, apoptosis, and senescence, as well as in inflammation and metabolism [32]. Furthermore,
SIRT1 promotes cancer cell survival and expansion through p53 inactivation, MYC activation, and EMT [33-35]. In this study, we investigated whether SIRT1 is involved in TGF- $\beta 1$-induced EMT during lung cancer cell migration and invasion, and found that its 
expression increased in TGF- $\beta 1$-induced NSCLC cells, but Sal treatment inhibited TGF- $\beta 1$-induced SIRT1 expression (Figure 3, 5).

SIRT1 and AMPK act as metabolic sensors that regulate energy metabolism based on nutritional status. They perform this role independently or cooperatively by coordinating with each other and sharing a common target molecule $[36,37]$. In several studies, SIRT1 induced phosphorylation and inactivation by AMPK in Thr344, thus promoting p53 acetylation and apoptosis [38]. In another study, AMPK was recognized as one of the downstream SIRT1 substrates and acted as a cellular metabolic stress sensor by activation via SIRT1 phosphorylation [20]. We confirmed, by upregulation or downregulation, the association between SIRT1 and AMPK. SIRT1 or AMPK downregulation reduced SIRT1 expression and AMPK phosphorylation of Sal in human NSCLC cells. Also, we confirmed that MMP-2 and MMP-9 expression increases or decreases by SIRT1 upregulation or AMPK, downregulation (Figure 3-5). The results of this study suggested that SIRT1 and AMPK interacted with the TGF$\beta 1$-induced EMT inhibition by Sal.

In conclusion, we demonstrated that Sal suppresses lung cancer cell migration and invasion by inhibiting TGF- $\beta 1$-induced EMT, and that it may be partially attributed to the AMPK/SIRT1 pathway. We also found that, for MMP-2 and MMP-9, the downregulation of AMPK/SIRT1 is involved in the TGF- $\beta 1$-induced EMT in A549 and H460 cells. These results suggest that the function and detailed mechanism of Sal's anti-cancer effects can help develop a new and promising treatment for lung cancer patients in the future.

\section{Abbreviations}

Sal: Salinomycin; NSCLC: Non-small cell lung cancer; EMT: Epithelial-to-mesenchymal transition; TGF- $\beta 1$ : Transforming growth factor- $\beta 1$; MTT: 3-(4,5-dimethyl-2-thiazolyl)-2,5-diphenyl-2H-tetrazoli um bromide; SDS-PAGE: Sodium dodecyl sulfate polyacrylamide gel electrophoresis; siRNA: Small interfering RNA; HDAC: Histone deacetylase; MMP: Matrix metalloproteinases.

\section{Acknowledgements}

The authors would like to thank Enago (www.enago.co.kr) for the English language review.

\section{Funding}

This research was supported by Basic Science Research Program through the National Research Foundation of Korea (NRF) funded by the Ministry of Education (2018R1D1A1B07050757), (2015R1D1A1
A01057580) and the Korea Health Technology R\&D Project through the Korea Health Industry Development Institute (KHIDI), funded by the Ministry of Health \& Welfare, Republic of Korea (HI15C1951).

\section{Author Contributions}

The authors have made the following declarations about their contributions: Conceived and designed: HKE, KHJ, SIS, OSH, KYS, and KHR. Development of methodology: HKE, KHJ, SIS, PC, JJW, PDS, OSH, KYS, and KHR. Acquisition of data: HKE, KHJ, SIS, JJW, PDS, KYS, and KHR. Analysis and interpretation of data: HKE, KHJ, SIS, PC, JJW, KYS, and KHR. Writing, review, and revision of the manuscript: HKE, KHJ, KYS, and KHR. Study supervision: KYS and KHR.

\section{Availability of data and materials}

The datasets used and/or analysed during the current study available from the corresponding author on reasonable request.

\section{Ethics approval and consent to participate}

The study was conducted in accordance with the Declaration of Helsinki, and the protocol was approved by the Institutional Animal Care and Use Committee (IACUC) at Wonkwang University (WKU18-83).

\section{Competing Interests}

The authors have declared that no competing interest exists.

\section{References}

1. Jung KW, Won YJ, Kong HJ, Oh CM, Cho H, Lee DH and Lee KH. Cancer statistics in Korea: incidence, mortality, survival, and prevalence in 2012. Cancer Res Treat 2015; 47:127-141.

2. $\mathrm{Xu}$ J Lamouille $\mathrm{S}$ and Derynck $\mathrm{R}$. TGF-beta-induced epithelial to mesenchymal transition. Cell Res 2009; 19:156-172.

3. Lee CM, Park JW, Cho WK, Zhou Y, Han B, Yoon PO, Chae J, Elias JA and Lee CG. Modifiers of TGF- $\beta 1$ effect or function as novel therapeutic targets of pulmonary fibrosis. Korean J Intern Med 2014; 29:281-290.

4. Cavallaro U and Christofori G. Cell adhesion and signalling by cadherins and Ig-CAMs in cancer. Nat Rev Cancer 2004; 4:118-132.

5. Thiery JP and Sleeman JP Complex networks orchestrate epithelial-mesenchymal transitions. Nat Rev Mol Cell Biol 2006; 7:131-142.

6. Lamouille S, Xu J and Derynck R. Molecular mechanisms of epithelial-mesenchymal transition. Nat Rev Mol Cell Biol 2014; 15:178-196.

7. Gomes LR, Terra LF, Sogayar MC and Labriola L. Epithelial-mesenchymal transition: implications in cancer progression and metastasis. Curr Pharm Biotechnol 2011; 12:1881-1890.

8. Labelle M, Begum S and Hynes RO. Direct signaling between platelets and cancer cells induces an epithelial-mesenchymal-like transition and promotes metastasis. Cancer Cell 2011; 20:576-590.

9. Bierie B and Moses HL. Tumour microenvironment: TGF beta: the molecular Jekyll and Hyde of cancer. Nat Rev Cancer 2006; 6:506-520.

10. Heldin $\mathrm{CH}$, Landström $\mathrm{M}$ and Moustakas A. Mechanism of TGF-beta signaling to growth arrest, apoptosis, and epithelial-mesenchymal transition. Curr Opin Cell Biol 2009; 21:166-176.

11. Zhu LQ, Zhen YF, Zhang Y, Guo ZX, Dai J and Wang XD. Salinomycin activates AMP-activated protein kinase-dependent autophagy in cultured osteoblastoma cells: a negative regulator against cell apoptosis. PLoS One 2013; 8:e84175.

12. Arafat $\mathrm{K}$, Iratni $\mathrm{R}$, Takahashi $\mathrm{T}$, Parekh $\mathrm{K}, \mathrm{Al}$ Dhaheri $\mathrm{Y}$, Adrian TE and Attoub S. Inhibitory Effects of Salinomycin on Cell Survival, Colony Growth, 
Migration, and Invasion of Human Non-Small Cell Lung Cancer A549 and LNM35: Involvement of NAG-1. PLoS One 2013; 8:e66931.

13. Gupta PB, Onder TT, Jiang G, Tao K, Kuperwasser C, Weinberg RA and Lander ES. Identification of selective inhibitors of cancer stem cells by high-through put screening. Cell 2009; 138: 645-659.

14. Fuchs D, Heinold A, Opelz G, Daniel V and Naujokat C. Salinomycin induces apoptosis and overcomes apoptosis resistance in human cancer cells. Biochem Biophys Res Commun 2009; 390:743-749.

15. Zhou Y, Liang C, Xue F, Chen W, Zhi X, Feng X, Bai X and Liang T. Salinomycin decreases doxorubicin resistance in hepatocellular carcinoma cells by inhibiting the $\beta$-catenin/TCF complex association via FOXO3a activation. Oncotarget 2015; 6:10350-10365.

16. Qu H, Ma B, Yuan HF, Wang ZY, Guo SJ and Zhang J. Effect of salinomycin on metastasis and invasion of bladder cancer cell line T24. Asian Pac J Trop Med $2015 ; 8: 578-582$.

17. Saxena NK, Taliaferro-Smith L, Knight BB, Merlin D, Anania FA, O'Regan RM and Sharma D. Bidirectional crosstalk between leptin and insulin-like growth factor-I signaling promotes invasion and migration of breast cancer cells via transactivation of epidermal growth factor receptor. Cancer Res 2008; 68:9712-9722.

18. Keese CR, Bhawe K, Wegener J and Giaever I. Real-time impedance assay to follow the invasive activities of metastatic cells in culture. Biotechniques 2002; 33:842-850.

19. Li T, Su L, Zhong N, Hao X, Zhong D, Singhal S and Liu X. Salinomycin induces cell death with autophagy through activation of endoplasmic reticulum stress inhuman cancer cells. Autophagy 2013; 9:1057-1068.

20. You J, Cheng J, Yu B, Duan C and Peng J. Baicalin, a Chinese Herbal Medicine, Inhibits the Proliferation and Migration of Human Non-Small Cell Lung Carcinoma(NSCLC) Cells, A549 and H1299, by Activating the SIRT1/AMPK Signaling Pathway. Med Sci Monit 2018; 24:2126-2133.

21. Curran S and Murray GI. Matrix metalloproteinases in tumour invasion and metastasis. J Pathol 1999; 189:300-308

22. Baek S, Lee YW, Yoon S, Baek SY, Kim BS and Oh SO. CDH3/P-Cadherin regulates migration of HuCCT1 cholangiocarcinoma cells. Anat Cell Biol 2010; 43:110-117.

23. Thiery JP. Epithelial-mesenchymal transitions in tumour progression. Nat Rev Cancer 2002; 2:442-454

24. Yang J and Weinberg RA. Epithelial-mesenchymal transition: at the crossroads of development and tumor metastasis. Dev Cell 2008; 14:818-829.

25. Kuo SZ, Blair KJ, Rahimy E, Kiang A, Abhold E, Fan JB, Wang-Rodriguez J, Altuna $X$ and Ongkeko WM. Salinomycin induces cell death and differentiation in head and neck squamous cell carcinoma stem cells despite activation of epithelial-mesenchymal transition and Akt. BMC Cancer 2012; 12:556.

26. Koeck S, Amann A, Huber JM, Gamerith G, Hilbe $W$ and Zwierzina $H$. The impact of metformin and salinomycin on transforming growth factor $\beta$-induced epithelial-to-mesenchymal transition in non-small cell lung cancer cell lines. Oncol Lett 2016; 11:2946-2952.

27. Li R, Dong T, Hu C, Lu J, Dai J and Liu P. Salinomycin repressed the epithelial-mesenchymal transition of epithelial ovarian cancer cells via downregulating Wnt/ $\beta$-catenin pathway. Onco Targets Ther 2017; 10:1317-1325.

28. Dong TT, Zhou HM, Wang LL, Feng B, Lv B and Zheng MH. Salinomycin selectively targets 'CD133+' cell subpopulations and decreases malignant traits in colorectal cancer lines. Ann Surg Oncol 2011; 18:1797-1804.

29. Monteverde T, Muthalagu N, Port J and Murphy DJ. Evidence of cancer-promotingroles for AMPK and related kinases. FEBS J 2015; 282:4658-4671.

30. Lee JH, Kim JH, Kim JS, Chang JW, Kim SB, Park JS and Lee SK. AMP-activated protein kinase inhibits TGF- $\beta$-, angiotensin II-, aldosterone-, high glucose-, andalbumin-induced epithelial-mesenchymal transition. Am J Physiol Renal Physiol 2013; 304:F686-F697.

31. Wang $X$, Pan $X$ and Song J. AMP-activated protein kinase is required for induction of apoptosis and epithelial-to-mesenchymal transition. Cell Signal 2010; 22:1790-1797.

32. Cen Y, Youn DY and Sauve AA. Advances in characterization of human sirtuin isoforms: chemistries, targets and therapeutic applications. Curr Med Chem 2011;18:1919-1935.

33. Kim JE, Chen J and Lou Z. DBC1 is a negative regulator of SIRT1. Nature 2008; 451:583-586

34. Yuan J, Minter-Dykhouse K and Lou Z. A c-Myc-SIRT1 feedback loop regulates cell growth and transformation. J Cell Biol 2009; 185:203-211.

35. Byles V, Zhu L, Lovaas JD, Chmilewski LK, Wang J, Faller DV and Dai Y. SIRT1 induces EMT by cooperating with EMT transcription factors and enhances prostatecancer cell migration and metastasis. Oncogene 2012; 31:4619-4629.

36. Cantó C, Jiang LQ, Deshmukh AS, Mataki C,Coste A, Lagouge M, Zierath JR and Auwerx J. Interdependence of AMPK and SIRT1 for metabolic adaptation to fastingand exercise in skeletal muscle. Cell Metab 2010; 11:213-219.

37. Hou X, Xu S, Maitland-Toolan KA, Sato K, Jiang B, Ido Y, Lan F, Walsh K, Wierzbicki M, Verbeuren TJ, Cohen RA and Zang M. SIRT1 regulates hepatocyte lipid metabolism through activating AMP-activated protein kinase. J Biol Chem 2008; 283:20015-20026.
38. Lee CW, Wong LL, Tse EY, Liu HF, Leong VY, Lee JM, Hardie DG, Ng IO and Ching YP. AMPK promotes p53 acetylation via phosphorylation and inactivation of SIRT1 in liver cancer cells. Cancer Res. 2012; 72:4394-4404 